\title{
Affective - Cognitive - Usability (ACU) Model Incorporating Eye Tracking Analysis for Redesigning the e-Commerce Website
}

\author{
Markus Hartono ${ }^{(凶)}$, Argo Hadi Kusumo, and Dwilita Aprilin Asikin \\ Department of Industrial Engineering, University of Surabaya, Surabaya, Indonesia \\ markusestaff.ubaya.ac.id
}

\begin{abstract}
This study discusses the investigation of how both cognitive and affective factors bring significant impact on the usability in e-commerce website selling consumer products. It raises a question of which one is more dominant, whether it is cognition or affect for consumer experience? It is a critical thing to investigate. Eye tracking analysis is utilized to emphasize concerns related to comfortable display. A case study on a popular e-commerce website of consumer products in Indonesia was taken to validate the proposed model. Through Structural Equation Modeling (SEM), it shows that affect was found to be more dominant than that of cognition in affecting to usability. In order to provide more applicable improvement strategy related to efficiency of display, eye tracking analysis was used. The analysis referred to metrics that have been designed in the research of Ehmke and Wilson [1] which focuses on the number of fixations and revisits in the Area of Interest (AOI). The most critical proposed improvement was that to change the location of the product price ordering menus so that they are adjacent to where the search results filter elements are located in that e-commerce website. Practical and theoretical implications were discussed as well.
\end{abstract}

Keywords: Affective $\cdot$ Cognitive $\cdot$ Usability $\cdot$ e-Commerce website $\cdot$ Kansei

\section{Introduction}

\subsection{Background and Research Motivation}

Both cognitive and affective process have been taken into account for both product and service interaction. It leads to the usability of product and service. Not only cognitive based, the product and service usability also consider the affect or emotional needs of customer. The cognitive aspect of usability is shown through ease of use, identification, download delay and trust, whereas the affective one is through colors, images, shapes, and perception of information system. Hence, a unified cognition and affect provides a comprehensive human information and processing system which leads to any forms of customer intention as a consequence.

Cognition alone is insufficient in representing a whole experience of customer interaction with product and services. Affect will complement this human-system interaction. 
As a result, both affective and cognitive evaluation will bring more complete information for product and service development. According to Khalid and Helander [2], affect or Kansei will make judgement faster than cognition. For instance, affect will be responsible for assessing whether the environment is safe or dangerous. Cognition is quite related to formulation of meaning and beliefs due to perceived information.

As discussed earlier, usability is positioned to be a consequence due to complex process of cognition and affect in service or product interaction. A recent study by Prastawa et al. [3] tried to build a comprehensive model of affective process, cognitive process, and usability taking into account e-learning as the empirical study involving undergraduate students as respondent. However, the opportunities for conducting this study are still prospective. Limitations on the diverse of service settings and also the number of respondents motivate this current study. Hence, it is still quite interesting to explore more the interaction of affective-cognitive-usability (known as ACU model) incorporating different service settings as a way to investigate the generalization of the proposed model.

\subsection{Problem Statement}

Studies on the relationship between affective, cognitive, and usability (ACU) is still relatively rare. Recent study by Hartono and Raharjo [4] shows that affect (as represented by Kansei) and cognition have proportional weight on customer loyalty. Cognition here is represented by overall satisfaction due to rational assessment of perceived service quality. More specifically, Kansei and cognition account for $24 \%$ and $28 \%$, respectively.

E-commerce website is a vital feature of online business information platforms, and it is full of complex customer mental process experience. Study by Prastawa et al. [3] shows that cognition is still found to be the primary determinant of usability. Once it is replicated to other product experience or service settings, the results could be different. Nevertheless, a study on ACU model in services is very potential to explore. Which one is more dominant whether cognitive or affective process in influencing the usability performance, is deemed to be quite interesting. It is especially for product or service designer in tackling issues on which product or service attributes are critical to customer.

\subsection{Objective and Question}

This study has two main objectives as follow. First, it is to examine and analyze the relationship among the constructs of affect, cognition, and usability (ACU) for e-commerce website of consumer products incorporating eye tracking analysis. A modified model of ACU (i.e., modification from [3] and an empirical study on a very popular e-commerce website in Indonesia) are reported. The second is that to formulate the improvement strategies for e-commerce website services based on the findings of path model above. Study on the investigation of e-commerce service attributes or components is interesting nowadays, especially in the pandemic since many people are involved in Work-fromHome (WfH) activities. It is so obvious the use of internet or online platform including e-commerce transaction is very intensive. 


\section{Methodology}

This study applied survey interview and face-to-face questionnaire as a powerful research method in exploring framework [5] and proven effective [6, 7]. Convenience sampling was used. Adopting the previous A-C-U framework [3], there were 3 hypotheses:

H1: Cognition has positive impact on Affect at the e-commerce website transaction $\mathrm{H} 2$ : Affect has positive impact on Usability at the e-commerce website transaction H3: Cognition has positive impact on Usability at the e-commerce website transaction

The respondents aged 19-24 years old with number of 56 subjects and were deemed sufficient for the Structural Equation Model Partial Least Square (SEM-PLS) [8] and with minimum of 39 sample [9]. The rationale is as follows. This is obtained from the average range of the number of samples needed to perform the analysis using the Structural Equation Model Partial Least Square (SEM-PLS) based on previous research. Based on previous research conducted by the Nielsen Norman Group, the minimum number of respondents in an eye tracking study in order to get stable results is 39 people. Thus, the determination of the number of samples of 56 people is deemed correct in conducting this research. This has also taken into account the possibility of failure in the recording of respondents in collecting eye tracking data.

The user being researched was given a task to do when the user accesses the ecommerce website which can be called a task. This task represents the core activity of e-commerce. The task is designed to create uniformity for all respondents who are tested using either the questionnaire method or eye tracking. The results of the questionnaire in the form of a Likert scale were analysed using the Structural Equation Model Partial Least Square (SEM-PLS) with the help of SmartPLS software. The results of data processing using the SmartPLS software answered the designed hypotheses.

\section{Results}

Using the SEM-PLS, the validity and reliability tests for the survey instrument were done. Through several iterations, the final path model was set, valid and reliable. It is shown in Fig. 1. The Goodness of Fit (GoF) of 0.8594 showed that the cognition and affect can explain $85.94 \%$ of the usability. All t-statistics values at all alternative hypotheses were greater than the significant value at the alpha of 5\% (i.e., 1.96). The relationship between $\mathrm{X} 1$ and $\mathrm{X} 2$ is 10.59 ; between $\mathrm{X} 1$ to $\mathrm{Y}$ is 3.97 ; and between $\mathrm{X} 2$ to $\mathrm{Y}$ is 4.42, where these three values were greater than 1.96. This means reject H0. Thus, based on these results it can be concluded that the cognitive and affective aspects had a significant effect on user usability in using the e-commerce website.

Hence, both cognition and affect had a significant effect on the usability. It shows that affect was more dominant than cognition in affecting usability. In other words, in a case of e-commerce, affect was more important than that of cognition.

Through quadrant analysis, subjected to user perception and factor loading of structural model, there were two critical attributes, i.e., (i) The user is aware of any errors occurred, and (ii) The user can cancel any orders made. In formulating improvement 

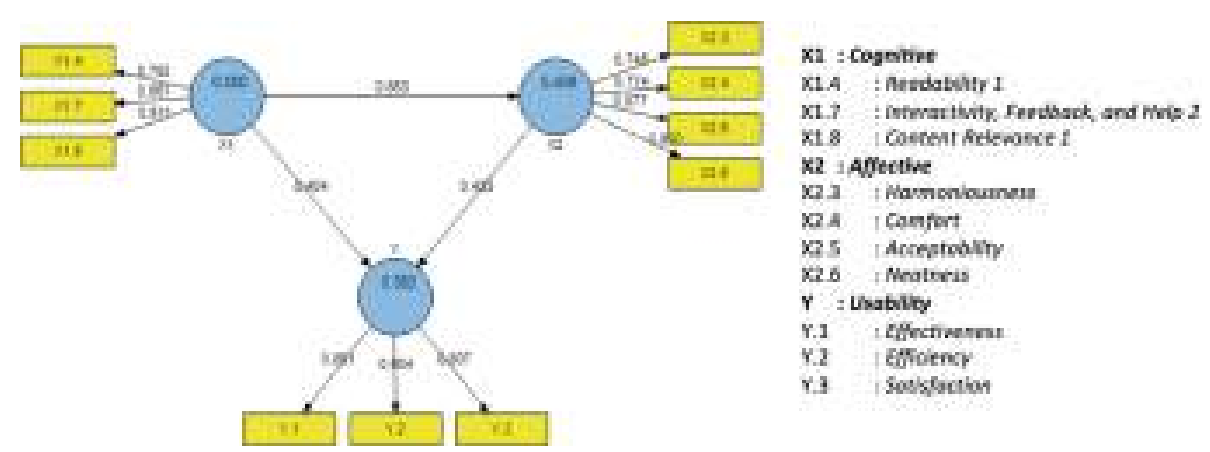

Fig. 1. A significant structural model Affective-Cognitive-Usability (ACU) in e-commerce website

strategy, eye tracking analysis was used according to the number of fixations and revisits in the Area of Interest (AOI). Both are related to error prevention.

\section{Discussion}

According to the findings of path model and hypotheses testing, cognition was proven significantly as the antecedent of affect. This confirms the previous study by Hartono and Tan [6]. Comparing the effect on usability, the affect construct was more dominant than that of the cognition. It was shown by the path coefficient of affect $(0.433)$ which was higher than that of the cognition (0.404) on usability. It was unique and interesting since the respondents' rationale and feeling was proportional when it came to the case of e-commerce website.

More specifically, in the usability attribute "Efficiency - I can achieve my goals quickly and economically when using the e-commerce website" was critical. Indeed, both rationale and emotion were merged and equally important when it was dealing with e-commerce website experience. Afterward, through eye tracking, the details of problem related to fixations and revisits on area of interest (AOI) and how to solve it were formulized. The average fixations and revisits were deemed to be sufficient input for improvement. An example of AOI for a certain task related to variable "error prevention" is provided in Fig. 2.

The error prevention issue was becoming the prominent concern. Some proposed improvement strategies were as follow. First, to change the location of the product price ordering elements so that they are adjacent to where the search results filter elements are located. Second, to provide a list entry containing words that are close to the keyword when the user types the keyword in the search box. Third, to provide word suggestions in the error description in the form of correcting keywords that can be clicked directly to go to the search for that word. Fourth, to remove the "Other" element and position the order cancellation element which can be directly selected in the order list view. One example of a comparison between the existing and proposed condition is shown in Fig. 3.

This study has limitations at the relatively small sample size, service setting, and previous research studies on the similar topic. 


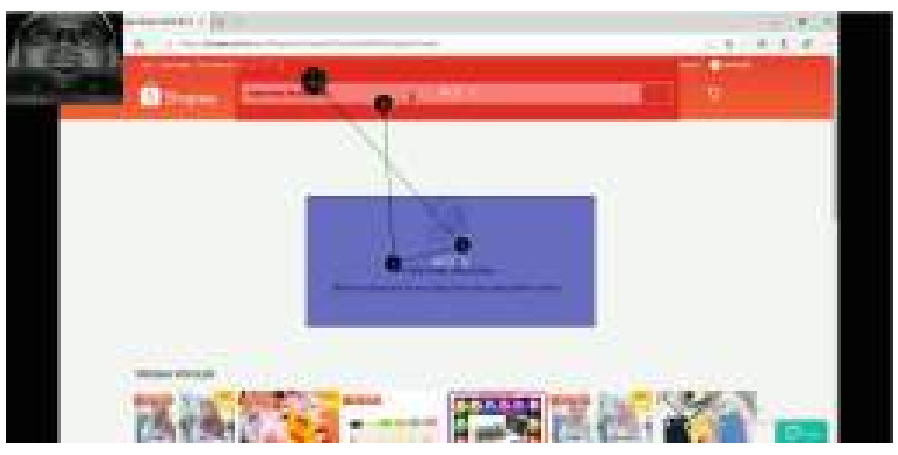

Fig. 2. AOI for task related to error prevention
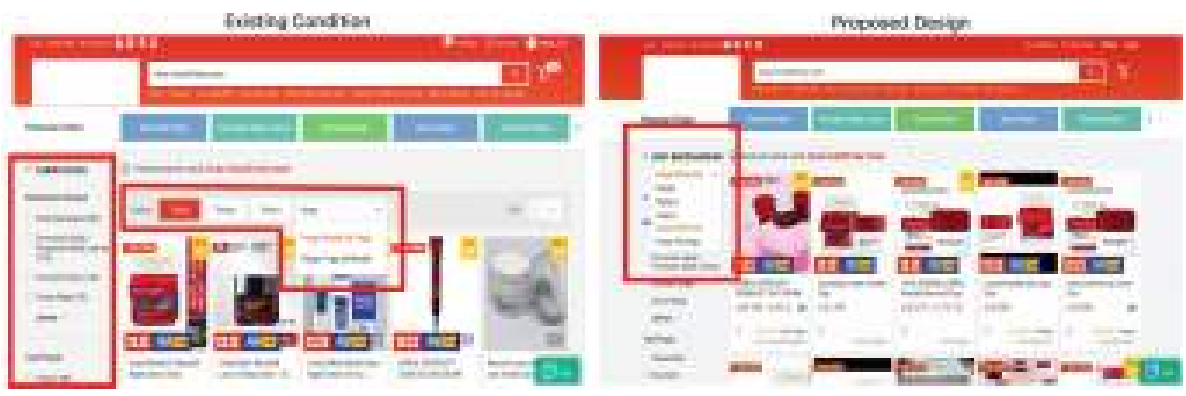

Fig. 3. A comparison between the existing condition and proposed design related to change of ordering and filtering product

\section{Conclusion}

This study has proposed and validated the model of affect, cognition, and usability (ACU) by taking into account an empirical study on e-commerce website of a popular business in Indonesia. It is hoped that the e-commerce service provider may use this study as a practical guidance for making their business more effectively and efficiently.

This research is expected to be useful for e-commerce companies and academics. For e-commerce companies, this study provides an illustration that the usability aspect of an e-commerce website is also part of the quality of the website, so it is important to pay attention to the website's performance in accordance with customer expectations as a user. The results of this study are also expected to provide guidelines or references for designers and developers of e-commerce websites in designing, developing and improving website designs so that they meet the usability aspect by paying attention to the cognitive and affective aspects. For the academic community, this research is expected to provide a reference on usability testing by considering cognitive and affective aspects which refer to the indicators of the Affective-Cognitive-Usability integration model through questionnaire instruments and eye tracking methods. 
Acknowledgment. This study was supported by the research grant from the Ministry of Research and Technology/National Research and Innovation Agency of Republic Indonesia 2020 under scheme of Basic Research of Higher Education Excellence (PDUPT) with theme of Kansei Engineering for Robust Design.

\section{References}

1. Ehmke, C., Wilson, S.: Identifying web usability problems from eye-tracking data. In: People and Computers XXI HCI.But Not as We Know It - Proceedings of HCI 2007: The 21st British HCI Group Annual Conference (2007)

2. Khalid, H.M., Helander, M.G.: Customer emotional needs in product design. Concurr. Eng. Res. Appl. 14(3), 197-206 (2006)

3. Prastawa, H., Ciptomulyono, U., Laksono-Singgih, M., Hartono, M.: The effect of cognitive and affective aspects on usability. Theor. Issues Ergon. Sci. 20(4), 507-531 (2019)

4. Hartono, M., Raharjo, H.: Exploring the mediating role of affective and cognitive satisfaction on the effect of service quality on loyalty. Total Qual. Manag. Bus. Excell. 26(9-10), 971-985 (2015)

5. Voss, C., Tsikriktsis, N., Frohlich, M.: Case study research in operations management. Int. J. Oper. Prod. Manag. 22(2), 195-219 (2002)

6. Hartono, M., Tan, K.C.: How the Kano model contributes to Kansei Engineering in services. Ergonomics 54(11), 987-1004 (2011)

7. Hartono, M.: The modified Kansei Engineering-based application for sustainable service design. Int. J. Ind. Ergon. 79, 102985 (2020)

8. Ulum, M., Tirta, I.M., Anggraeni, D.: Analisis structural equation modeling (SEM) untuk sampel kecil dengan pendekatan partial least square (PLS). Prosiding Seminar Nasional Matematika Universitas Jember, pp. 1-15 (2014)

9. Nielsen, J.: How many test users in a usability study? (2012). https://www.nngroup.com/art icles/how-many-test-users/ 
Lecture Notes in Networks and Systems 223

Nancy L. Black · W. Patrick Neumann · lan Noy Editors

Proceedings of the 21st Congress of the International Ergonomics

Association (IEA 2021)

Volume V: Methods \& Approaches

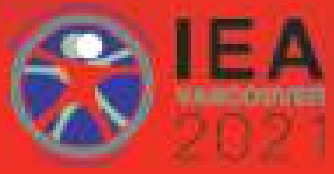

Springer 


\section{Lecture Notes in Networks and Systems}

\section{Volume 223}

\section{Series Editor}

Janusz Kacprzyk, Systems Research Institute, Polish Academy of Sciences, Warsaw, Poland

\section{Advisory Editors}

Fernando Gomide, Department of Computer Engineering and Automation-DCA, School of Electrical and Computer Engineering-FEEC, University of CampinasUNICAMP, São Paulo, Brazil

Okyay Kaynak, Department of Electrical and Electronic Engineering, Bogazici University, Istanbul, Turkey

Derong Liu, Department of Electrical and Computer Engineering, University of Illinois at Chicago, Chicago, USA; Institute of Automation, Chinese Academy of Sciences, Beijing, China

Witold Pedrycz, Department of Electrical and Computer Engineering, University of Alberta, Alberta, Canada; Systems Research Institute, Polish Academy of Sciences, Warsaw, Poland

Marios M. Polycarpou, Department of Electrical and Computer Engineering, KIOS Research Center for Intelligent Systems and Networks, University of Cyprus, Nicosia, Cyprus

Imre J. Rudas, Óbuda University, Budapest, Hungary

Jun Wang, Department of Computer Science, City University of Hong Kong, Kowloon, Hong Kong 
The series "Lecture Notes in Networks and Systems" publishes the latest developments in Networks and Systems - quickly, informally and with high quality. Original research reported in proceedings and post-proceedings represents the core of LNNS.

Volumes published in LNNS embrace all aspects and subfields of, as well as new challenges in, Networks and Systems.

The series contains proceedings and edited volumes in systems and networks, spanning the areas of Cyber-Physical Systems, Autonomous Systems, Sensor Networks, Control Systems, Energy Systems, Automotive Systems, Biological Systems, Vehicular Networking and Connected Vehicles, Aerospace Systems, Automation, Manufacturing, Smart Grids, Nonlinear Systems, Power Systems, Robotics, Social Systems, Economic Systems and other. Of particular value to both the contributors and the readership are the short publication timeframe and the world-wide distribution and exposure which enable both a wide and rapid dissemination of research output.

The series covers the theory, applications, and perspectives on the state of the art and future developments relevant to systems and networks, decision making, control, complex processes and related areas, as embedded in the fields of interdisciplinary and applied sciences, engineering, computer science, physics, economics, social, and life sciences, as well as the paradigms and methodologies behind them.

Indexed by SCOPUS, INSPEC, WTI Frankfurt eG, zbMATH, SCImago.

All books published in the series are submitted for consideration in Web of Science.

More information about this series at http://www.springer.com/series/15179 
Nancy L. Black - W. Patrick Neumann • Ian Noy

Editors

Proceedings of the $21 \mathrm{st}$ Congress of the International Ergonomics Association (IEA 2021)

Volume V: Methods \& Approaches

Springer 


\section{Editors}

Nancy L. Black

Département de génie mécanique

Université de Moncton

Moncton, NB, Canada

Ian Noy

Toronto, ON, Canada

\author{
W. Patrick Neumann \\ Department of Mechanical and Industrial \\ Engineering \\ Ryerson University \\ Toronto, ON, Canada
}

\author{
ISSN 2367-3370 \\ Lecture Notes in Networks and Systems \\ ISBN 978-3-030-74613-1 \\ https://doi.org/10.1007/978-3-030-74614-8 \\ ISSN 2367-3389 (electronic)
}

(C) The Editor(s) (if applicable) and The Author(s), under exclusive license

to Springer Nature Switzerland AG 2022

This work is subject to copyright. All rights are solely and exclusively licensed by the Publisher, whether the whole or part of the material is concerned, specifically the rights of translation, reprinting, reuse of illustrations, recitation, broadcasting, reproduction on microfilms or in any other physical way, and transmission or information storage and retrieval, electronic adaptation, computer software, or by similar or dissimilar methodology now known or hereafter developed.

The use of general descriptive names, registered names, trademarks, service marks, etc. in this publication does not imply, even in the absence of a specific statement, that such names are exempt from the relevant protective laws and regulations and therefore free for general use.

The publisher, the authors and the editors are safe to assume that the advice and information in this book are believed to be true and accurate at the date of publication. Neither the publisher nor the authors or the editors give a warranty, expressed or implied, with respect to the material contained herein or for any errors or omissions that may have been made. The publisher remains neutral with regard to jurisdictional claims in published maps and institutional affiliations.

This Springer imprint is published by the registered company Springer Nature Switzerland AG The registered company address is: Gewerbestrasse 11, 6330 Cham, Switzerland 


\section{Preface}

The International Ergonomics Association (IEA) is the organization that unites Human Factors and Ergonomics (HF/E) associations around the world. The mission of the IEA is "to elaborate and advance ergonomics science and practice, and to expand its scope of application and contribution to society to improve the quality of life, working closely with its constituent societies and related international organizations" (IEA, 2021). The IEA hosts a world congress every three years creating the single most important opportunity to exchange knowledge and ideas in the discipline with practitioners and researchers from across the planet. Like other IEA congresses, IEA2021 included an exciting range of research and professional practice cases in the broadest range of Human Factors and Ergonomics (HF/E) applications imaginable. While the conference was not able to host an in-person meeting in Vancouver, Canada, as planned by the host Association of Canadian Ergonomists/Association canadienne d'ergonomie, it still featured over 875 presentations and special events with the latest research and most innovative thinkers. For this congress, authors could prepare a chapter for publication, and $60 \%$ chose to do so. The breadth and quality of the work available at IEA2021 are second to none-and the research of all authors who prepared their publication for this congress is made available through the five volumes of these proceedings.

The International Ergonomics Association defines Human Factors and Ergonomics (HF/E) synonymously as being:

the scientific discipline concerned with the understanding of interactions among humans and other elements of a system, and the profession that applies theory, principles, data and methods to design in order to optimize human well-being and overall system performance.

Practitioners of ergonomics and ergonomists contribute to the design and evaluation of tasks, jobs, products, environments and systems in order to make them compatible with the needs, abilities and limitations of people.

Ergonomics helps harmonize things that interact with people in terms of people's needs, abilities and limitations. (https://iea.cc/definition-and-domains-of-ergonomics/) 
The breadth of issues and disciplines suggested by this definition gives one pause for thought: what aspect in our lives is not in some way affected by the design and application of HF/E? For designers and managers around the world, a similar realization is growing: every decision made in the design and application of technology has implications for the humans that will interact with that system across its lifecycle. While this can be daunting, the researchers and professionals who participated in IEA2021 understand that, by working together across our disciplines and roles, we can achieve these lofty ambitions. This is especially relevant as we continue our collective journey into an increasingly "interconnected world"- the theme for the 21st IEA Congress. With the rise of a myriad of technologies as promulgated by Industry 4.0 proponents, we need now, more than ever, the skills and knowledge of HF/E researchers and practitioners to ensure that these tools are applied in a human-centric way towards resilient and sustainable systems that provide an enduring and sustainable road to prosperity-as advocated in the new Industry 5.0 Paradigm (Breque et al. 2021). Where the trend of Industry 4.0 aims primarily at encouraging technology purchasing and application, Industry 5.0 includes goals of resiliency and sustainability for both humans and our planet. These proceedings provide examples of research and development projects that illustrate how this brighter, human-centred future can be pursued through "Ergonomie 4.0", as stated in the French theme of the Congress.

While the theme of the Congress concerns human interactions within a rapidly evolving cyber-physical world, the devastating impact of the COVID-19 pandemic has given an added dimension to the Congress theme and its delivery model. As the pandemic began to engulf the world, the traditional in-person Congress became increasingly less viable and gave way to the creation of a hybrid model as a means to enhance international participation. In early 2021, it became clear that holding an in-person event would not be possible; hence, the Congress was converted to a fully virtual event. The uncertainty, mounting challenges and turbulent progression actually created new possibilities to engage the global HF/E community in ways that were never previously explored by the IEA. Indeed, one of the scientific tracks of the congress focuses explicitly on HF/E contributions to cope with COVID-19, and readers will find some submissions to other tracks similarly focus on what HF/E practitioners and researchers bring to the world during this pandemic period. This journey epitomizes broader transformative patterns now underway in society at large and accentuates the urgency for resilience, sustainability, and healthy workplaces. No doubt, the notion of globalization will be redefined in the wake of the pandemic and will have far-reaching implications for the connected world and for future society, and with new paradigms emerge a host of new human factors challenges. The breadth of topics and issues addressed in the proceedings suggests that the HF/E community is already mobilizing and rising to these emerging challenges in this, our connected world.

IEA2021 proceedings includes papers from 31 scientific tracks and includes participants from 74 countries across 5 continents. The proceedings of the $21 \mathrm{st}$ triennial congress of the IEA-IEA2021 - exemplify the diversity of HF/E, and of the association, in terms of geography, disciplines represented, application 
domains, and aspects of human life cycle and capability being considered. Our diversity mirrors the diversity of humans generally and is a strength as we learn to weave our knowledge, methods, and ideas together to create a more resilient and stronger approach to design than is achievable individually. This is the strength of the IEA congresses, in the past, in the current pandemic-affected 21 st occasion, and in the future. There is no other meeting like it.

A substantial number of works were submitted for publication across the Scientific Tracks at IEA2021. This gave us the happy opportunity to group contents by common threads. Each volume presents contents in sections with papers within the track's section presented in alphabetical order by the first author's last name. These proceedings are divided into five volumes as follows:

\section{VOLUME 1: SYSTEMS AND MACROERGONOMICS (ISBN 978-3-030-74601-8)}

Activity Theories for Work Analysis and Design (ATWAD)

Systems HF/E

Ergonomic Work Analysis and Training (EWAT)

HF/E Education and Professional Certification Development

Organisation Design and Management (ODAM)

\section{VOLUME 2: INCLUSIVE AND SUSTAINABLE DESIGN (ISBN 978-3-030-74604-9)}

Ageing and Work

Ergonomics for children and Educational Environments

Ergonomics in Design for All

Gender and Work

Human Factors and Sustainable Development

Slips Trips and Falls

Visual Ergonomics

\section{VOLUME 3: SECTOR BASED ERGONOMICS (ISBN 978-3-030-74607-0)}

Practitioner Case Studies

Aerospace Ergonomics

Agricultural Ergonomics

Building and Construction Ergonomics

Ergonomics in Manufacturing

HF/E in Supply Chain Design and Management

Transport Ergonomics and Human Factors

\section{VOLUME 4: HEALTHCARE AND HEALTHY WORK (ISBN 978-3-030-74610-0)}

Health and Safety

Healthcare Ergonomics 
HF/E Contribution to Cope with Covid-19

Musculoskeletal Disorders

VOLUME 5: METHODS \& APPROACHES (ISBN 978-3-030-74613-1)

Affective Design

Anthropometry

Biomechanics

Ergonomics in Advanced Imaging

Human Factors in Robotics

Human Modelling and Simulation

Neuroergonomics

Working with Computer Systems

These volumes are the result of many hours of work, for authors, Scientific Track Managers and their reviewer teams, student volunteers, and editors. We are grateful to Springer for making it available to you in book form and are confident you will find these works informative and useful in your own efforts to create a better, more human-centred future.

\section{References}

Breque, M., De Nul, L., Petridis, A., 2021. Industry 5.0: Towards More Sustainable, Resilient and Human-Centric Industry, in: Innovation, E.D.-G.f.R.a. (Ed.), Policy Brief. European Commission, Luxembourg, p. 48. https://ec. europa.eu/info/news/industry-50-towards-more-sustainable-resilient-andhuman-centric-industry-2021-jan-07_en

International Ergonomics Association (2021) Definitions and Domains of Ergonomics. https://iea.cc/definition-and-domains-of-ergonomics/; accessed March, 2021

Nancy L. Black

W. Patrick Neumann

IEA2021 Scientific Co-chairs

Ian Noy

IEA2021 Conference Chair 


\section{IEA2021 Acknowledgements}

The IEA Congress organizing committee acknowledges many individuals whose contributions to the event have been invaluable to its success.

First and foremost, we acknowledge with deep appreciation the tremendous work of Steve Marlin, CEO of Prestige Accommodations, International Inc. His firm, hired to assist with organizing and executing the Congress, delivered unparalleled service throughout the planning process. Tragically, Steve passed away in early 2021. He provided outstanding support and wise counsel, always with a smile. $\mathrm{He}$ is sorely missed. We remain indebted to the Prestige staff, whose expertise and outstanding professionalism guided us through the planning process. In particular, we are grateful to Laurie Ybarra, Sr. Meetings Manager, who oversaw the many diverse aspects of our ever-changing plans and Christine Reinhard, Director of Operations, who skilfully managed the budget, website and registration system. Laurie and Christine's friendly approach, and their unique combination of technical and interpersonal skills, made it a pleasure to work with them. Marie-Hélène Bisaillon, Executive Director of the Association of Canadian Ergonomists/ Association canadienne d'ergonomie, supported their work.

The Organizing Committee is also indebted to those contributors who were instrumental in developing and promoting IEA2021. Joanne Bangs, our freelance Communications Specialist, provided engaging news blogs and other promotional collateral to help get the word out about the Congress. Sadeem Qureshi (Ryerson University), Elizabeth Georgiou, Elaine Fung, and Michelle Lam (Simon Fraser University) helped to create widespread awareness of the Congress as well as the $\mathrm{HF} / \mathrm{E}$ field and profession through creative use of digital and social media. We are also grateful to those who worked diligently to ensure that the Congress provided meaningful opportunities for students and early career researchers, including Daniel P. Armstrong and Christopher A.B. Moore (University of Waterloo), Owen McCulloch (Simon Fraser University), Dora Hsiao (Galvion, Inc.), Chelsea DeGuzman and Joelle Girgis (University of Toronto), and Larissa Fedorowich (Associate Ergonomist, self-employed). The ePoster presentation option, new to IEA triennial congresses in 2021, was defined with care by Anne-Kristina Arnold (Simon Fraser University). Colleen Dewis (Dalhousie University) was key to 
interpreting our technical submission software and adapting its capacities to our needs. Hemanshu Bhargav (Ryerson University), Rachel Faust (Université de Québec à Montréal), Myriam Bérubé (Université de Montréal), Charlotte Bate, Vanessa DeVries, Caleb Leary, and Marcelo Zaharur (Fanshawe College), Tobi Durowoju (EWI Works), Issa Kaba Diakite, Mariam Keita, Mouhamadou Pléa Ndour, Shelby Nowlan, Faouzi Mahamane Ouedraogo, Jenna Smith, and Israël Muaka Wembi (Université de Moncton), and the aforementioned Larissa Fedorowich assisted with technical submission database verification and clean-up. We are particularly grateful that so many came to us through the Association of Canadian Ergonomists/Association canadienne d'ergonomie, witnessing to the active and motivated ergonomics and human factors community in IEA2021's host country.

The organizers are especially grateful to our sponsors, whose generous contributions made the Congress possible and readily accessible to the global HF/E community. Their recognition of the Congress as a valuable opportunity to advance the field of HF/E, as well as their steadfast support throughout a very trying planning period, was critical to the success of the Congress. The IEA 2021 sponsors include:

Benefactor Level:

Amazon.com, Inc.

Platinum Level:

Anonymous

Diamond Level:

Healthcare Insurance Reciprocal of Canada

Gold Level:

Huawei Technologies Canada

Institute for Work and Health (Ontario)

WorkSafe BC

Silver Level:

Fanshawe College

Simon Fraser University

Aptima, Inc. 


\section{Organization}

\section{IEA2021 Organizing Committee}

\section{IEA2021 Congress Chair}

Ian Noy

HFE Consultant and Forensic Expert, Toronto, Ontario, Canada

\section{Technical Program Committee Co-chairs}

Nancy L. Black

W. Patrick Neumann
Department of Mechanical Engineering, Faculté d'ingénierie, Université de Moncton, Canada

Human Factors Engineering Lab, Department of Mechanical and Industrial Engineering, Ryerson University, Canada

\section{Media Outreach}

Hayley Crosby

Options Incorporated, Canada

\section{Developing Countries}

Manobhiram (Manu) Nellutla

Actsafe Safety Association, Canada

ePosters Coordinator

Anne-Kristina Arnold

\section{Exhibits Coordinator}

Abigail Overduin
Workplace Health Services, The University of British Columbia, Canada 


\section{Early Career Researcher Program Coordinator}

Sadeem Quershi

\section{Media Relations}

Heather Kahle

Jenny Colman

\section{Events/Social}

Gina Vahlas

Era Poddar

Alison Heller-Ono
Human Factors Engineering Lab, Department of Mechanical and Industrial Engineering, Ryerson University, Canada

Human Factors Specialist/Ergonomist, WorkSafeBC, Canada

Human Factor Specialist, Risk Analysis Unit, WorkSafeBC, Canada

Human Factors Specialist/Ergonomist,

Risk Analysis Unit, WorkSafeBC, Canada Specialist Safety Advisor-Ergonomics,

Manufacturing Safety Alliance of BC, Canada CEO, Worksite International, USA

\section{French Language Coordinator}

François Taillefer

Faculté des sciences, Université de Québec à Montréal, Canada

\section{Communications Coordinator}

Joanne Bangs

Free-lance consultant, USA

\section{EasyChair Platform Technical Liaison}

Colleen Dewis

Department of Industrial Engineering, Dalhousie University, Canada

\section{Scientific Committee of IEA2021}

Nancy L. Black (Co-chair)

W. Patrick Neumann (Co-chair)

Wayne Albert

Sara Albolino

Thomas Alexander

Anne-Kristina Arnold
Université de Moncton, Canada

Ryerson University, Canada

University of New Brunswick, Canada Director Centre for Patient Safety Tuscany region Federal Institute for Occupational Safety and Health (BAUA), Germany Simon Fraser University, Canada 
Pascal Béguin

Tommaso Bellandi

Klaus Bengler

Yuval Bitan

Ivan Bolis

Tim Bosch

Richard Bowman

Guy André Boy

Karen Bredenkamp

Ole Broberg

Katie Buckley

Robin Burgess-Limerick

Peter Burns

Chien-Chi (Max) Chang

Andy S. K. Cheng

Pieter Coenen

Teresa Cotrim

Ann Marie Dale

Jonathan Davy

Enrique De la Vega

Catherine Delgoulet

Michiel de Looze

Colleen Dewis

Clark Dickerson

Francisco José de Castro

Moura Duarte

Tamsyn Edwards

Georg Effenberger

Echezona Nelson Dominic

Ekechukwu

Antonella Frisiello

Carlos Manuel Escobar

Galindo

Anindya Ganguli

Richard Gardner
Institut d'Études du Travail de Lyon (IETL) Université Lumière Lyon 2, France

Northwest Trust - Regional Health Service of Tuscany, Italy

Technische Universität München, Germany

Ben-Gurion University of the Negev,

University of Toronto, Israel

Universidade Federal da Paraíba, Brazil

TNO, Netherlands

Intertile Research Pty Ltd, Australia

CentraleSupélec (Paris Saclay University),

ESTIA Institute of Technology, France

Magic Leap, USA

Technical University of Denmark, Denmark

University of Melbourne, Australia

University of Queensland, Australia

Transport Canada, Canada

National Tsing Hua University, Taiwan

Hong Kong Polytechnique University,

Hong Kong

Amsterdam UMC (VUmc location), Netherlands

University of Lisbon, Portugal

Washington University in St. Louis, USA

Rhodes University, South Africa

TECNM/Instituto Technologico de Hermosillo,

Mexico

CRTD, Conservatoire National des Arts et

Métiers (CNAM), France

TNO, Netherlands

Dalhousie University, Canada

University of Waterloo, Canada

Federal University of Rio de Janeiro, Brazil

San Jose State University, NASA Ames

Research Center, USA

AUVA-Hauptstelle, Austrian Ergonomics

Society, Austria

University of Nigeria, Nigeria

LINKS Foundation, Italy

University of Nottingham, Universidad Peruana

Cayetano Heredia, Peru

Bureau of Indian Standards (BIS), Bharat Heavy

Electricals Ltd. (BHEL), India

Boeing Research \& Technology, USA 
Rafael E. Gonzalez

Ewa Górska

Maggie Graf

Alma Maria Jennifer

Gutierrez

Jukka Häkkinen

Gregor Harih

Veerle Hermans

Dora Hsiao

Laerte Idal Sznelwar

Rauf Iqbal

Nicole Jochems

Marie Laberge

Fion C. H. Lee

Yue (Sophia) Li

Peter Lundqvist

Neil Mansfield

Márcio Alves Marçal

Blake McGowan

Ranjana Mehta

Marijke Melles

Marino Menozzi

Francisco Octavio Lopez

Millan

Karen Lange Morales

Ruud N. Pikaar

Dimitris Nathanael

Yee Guan Ng

Jodi Oakman

Udoka Arinze Chris Okafor

Paulo Antonio Barros

Oliveira

Vassilis Papakostopoulos

Maria Pascale
Bolivarian University, Petróleos de Venezuela, S.A. (PDVSA), Venezuela

University of Ecology and Management in Warsaw, Poland

International Ergonomics Association Professional Standards and Education, Certification Sub-committee, Switzerland

De La Salle University-Manila, Philippines

University of Helsinki, Finland

University of Maribor, Slovenia

Vrije Universiteit Brussel, Belgium

Revision Military, Canada

Universidade de São Paulo, Brazil

National Institute of Industrial

Engineering (NITIE), India

University of Luebeck, Germany

Université de Montréal, Centre de recherche du CHU Ste-Justine, Canada

UOW College Hong Kong, Hong Kong

KITE, Toronto Rehabilitation InstituteUniversity Health Network, Canada

SLU - Swedish University of Agricultural Sciences, Sweden

Nottingham Trent University, UK

Universidade Federal dos Vales do Jequitinhonha e do Mucuri, Brazil

VelocityEHS, USA

Texas A\&M University, USA

Delft University of Technology, Netherlands

Swiss Federal Institute of Technology,

ETH Zurich, Switzerland

TECNM/Instituto Tecnológico de Hermosillo, Mexico

Universidad Nacional de Colombia, Colombia ErgoS Human Factors Engineering, Netherlands National Technical University of Athens, Greece Universiti Putra Malaysia, Malaysia

La Trobe University, Australia

University of Lagos, Nigeria

Federal University of Rio Grande do Sul, Brazil

University of the Aegean, Greece

Uruguayan Association of Ergonomics

(AUDErgo), Uruguay 
Gunther Paul

Chui Yoon Ping

Jim Potvin

Valérie Pueyo

Sadeem Qureshi

Sudhakar Rajulu

Gemma Read

David Rempel

Raziel Riemer

Michelle M. Robertson

Martin Antonio Rodriguez

Gustavo Rosal

Patricia H. Rosen

Ken Sagawa

Paul M. Salmon

Marta Santos

Sofia Scataglini

Lawrence J. H. Schulze

Rosemary Ruiz Seva

Fabio Sgarbossa

Jonas Shultz

Anabela Simões

Sarbjit Singh

John Smallwood

Lukáš Šoltys

Isabella Tiziana Steffan

Daryl Stephenson

Gyula Szabó

Shamsul Bahri Mohd Tamrin Andrew Thatcher

Giulio Toccafondi
James Cook University, Australia

Singapore University of Social Sciences, Singapore

McMaster University, Canada

Université Lumière Lyon 2, France

Ryerson University, Canada

NASA - Johnson Space Center, USA

University of the Sunshine Coast, Australia

University of California Berkeley;

University of California San Francisco, USA

Ben-Gurion University of the Negev, Israel

Office Ergonomics Research Committee,

Northeastern University, University

of Connecticut, University of California,

Berkeley, USA

Universidad Tecnológica Nacional Buenos

Aires FRBA, Argentina

UNE (Spanish Association for Standardisation), Spain

Federal Institute for Occupational Safety

and Health (BAUA), Germany

AIST, Japan

University of the Sunshine Coast, Australia

Universidade do Porto, Portugal

University of Antwerp, Belgium

University of Houston, USA

De La Salle University, Philippines

Norwegian University of Science and Technology, Norway

Health Quality Council of Alberta, University of Calgary, Canada

University Lusófona, Portugal

National Institute of Technology Jalandhar, India

Nelson Mandela University, South Africa

Czech Ergonomics Association, Czech Republic

STUDIO STEFFAN_-Progettazione \& Ricerca

(Design \& Research), Italy

Occupational Health Clinics for Ontario Workers,

Canada

Hungarian Ergonomics Society, Hungary

Universiti Putra Malaysia, Malaysia

University of the Witwatersrand, South Africa

Center for Clinical Risk Management and Patient

Safety GRC, WHO Collaborating Center,

Florence, Italy 
Andrew Todd

Judy Village

Christian Voirol

Michael Wichtl

Amanda Widdowson

Sascha Wischniewski
Rhodes University, South Africa

University of British Columbia, Canada

University of Applied Sciences Western

Switzerland, University of Montreal,

Switzerland

AUVA-Hauptstelle, Austrian Ergonomics

Society, Austria

Chartered Institute of Ergonomics and Human

Factors (CIEHF), Thales, UK

Federal Institute for Occupational Safety

\& Health (BAuA), Germany 


\section{Contents}

Part I: Affective Design (Edited by Rosemary Ruiz Seva)

Design for UX in Flexible Offices - Bringing Research

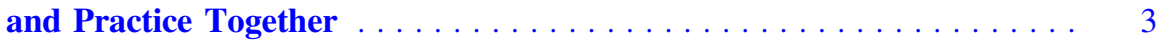

Antonio Cobaleda-Cordero and Maral Babapour

Outlining Experience and Well-Being in the Interaction

with Social Media Apps . . . . . . . . . . . . . . . . . . . . . . . . 12

Beatriz de Paulo and Manuela Quaresma

Affective Trash Bin Signage to Promote Waste Segregation . . . . . . . . . 20

Arvidas Kio Dy, Margarita Lazo, Andreana Gabrielle Santos,

and Rosemary Seva

Analysis of Geometric Features of 3D Shapes on Perception of Product

Appearance for Visual Brand Affiliation . . . . . . . . . . . . . 3

Matthias Sebastian Fischer, Daniel Holder, and Thomas Maier

Affective - Cognitive - Usability (ACU) Model Incorporating

Eye Tracking Analysis for Redesigning the e-Commerce Website

Markus Hartono, Argo Hadi Kusumo, and Dwilita Aprilin Asikin

The Functions of Computer-Mediated Touch at a Distance:

An Interactionist Approach

Robin Héron, Stéphane Safin, Michael Baker, and Françoise Détienne

Merging Total Design and User Centered Design for Designing a Mountable Toy: Achieving a Useful, Functional

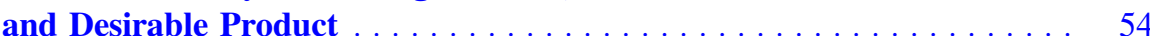

Julieta María Covarrubias Cruz, María Fernanda De La Rocha Barbosa, Fernanda Santos Rivera, and Pilar Hernández-Grageda

Behavioral and Cognitive Methods to Assess Users and Assist Physical

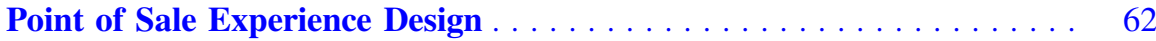

Paulo Eduardo Hauqui Tonin 
Design Process of a Mountable Toy Based on Total Design and User Centered Design Methodologies

Ana Sofía Olivares Jiménez, María Inés Ibarra Caballero,

Lilia Atziri Urías Dueñas, and Pilar Hernández-Grageda

\section{Part II: Anthropometry (Edited by Karen Bredenkamp)}

Anthropometric Indices and Nutritional Status of Infants in Nigeria - A Preliminary Study

Echezona Nelson Dominic Ekechukwu, Chiamaka Chinyere Anyaene,

Ogechukwu Ikefuna, Emmanuel Nwabueze Aguwa,

Israel Chijioke Iroezindu, Theodora A. Okeke, and Susan U. Arinze-Onyia

Mexican Older-Adult Sitting and Standing Anthropometric

Dimensions. Comparison with Other Populations.

Elvia Luz González-Muñoz, Rosalio Avila Chaurand,

John A. Rey Galindo, and Gabriel Ibarra Mejia

Firefighters' Anthropometrics: A Comparison Between Two

Portuguese Fire Brigades

Anna S. P. Moraes, Miguel A. F. Carvalho, Rachel S. Boldt,

Fernando B. N. Ferreira, Susan P. Ashdown, and Linsey Griffin

A Motion Capture System for Hand Movement Recognition .

Graciela Rodríguez-Vega, Dora Aydee Rodríguez-Vega,

Xiomara Penelope Zaldívar-Colado, Ulises Zaldívar-Colado,

and Rafael Castillo-Ortega

Hand Shape Modeling for the Mexican Population

Graciela Rodríguez-Vega, Xiomara Penelope Zaldívar-Colado,

Ulises Zaldívar-Colado, Enrique Javier De la Vega-Bustillos, and Dora Aydee Rodríguez-Vega

\section{Part III: Biomechanics (Edited by Rauf Iqbal)}

Effects of a Back-Support Exoskeleton on Pelvis-Thorax Kinematics and Coordination During Lifting . . . . . . . . . . . . . . . . . 131

Sivan Almosnino, Rong Huangfu, and Jessica Cappelletto

Measurement of Work-Related Physical Workloads - Proposal

for a Body Region-Related Categorization System .

Rolf Ellegast, Britta Weber, Christoph Schiefer, Kai Heinrich, and Ingo Hermanns-Truxius

Optimization of Product Handle Material Mechanical Properties

for Improved Ergonomics Using Finite Element Method

and Subjective Response . . . . . . . . . . . . . . . . . . . . . 148

Gregor Harih, Andrej Cupar, Jasmin Kaljun, and Bojan Dolšak 
Evaluation of Force Exertion Strategies During Repetitive Lifting/

Lowering Tasks Based on Time-Frequency Analysis

Kazuki Hiranai, Miho Yaji, and Akihiko Seo

A Wearable Device to Assess the Spine Biomechanical Overload

in a Sample of Loggers

Federica Masci, Giovanna Spatari, Concetto Mario Giorgianni,

Sara Bortolotti, John Rosecrance, and Claudio Colosio

Relationship of Floor Material and Fall Risk Assessment During

Descending Stairs

Takeshi Sato, Mizuki Nakajima, Ryota Murano, Macky Kato,

and Kimie Nakajima

PEPPA - Exchange Platform for Measurements of Occupational

Physical Activity and Physical Workload .

Christoph Schiefer, Vera Schellewald, Stefan Heßling, Ingo Hermanns-Truxius, Kévin Desbrosses, Marjolein Douwes,

Francesco Draicchio, Henrik Enquist, Mikael Forsman, Nidhi Gupta, Andreas Holtermann, Reinier Konemann, Norbert Lechner, Peter Loewis, Satu Mänttäri, Svend Erik Mathiassen, Andrew Pinder, Peter Schams, Marianne Schust, Michaela Strebl, Kaj Bo Veiersted, Britta Weber, and Rolf Ellegast

Biomechanical Simulation and a Detailed Analysis

of the Roadside Cleaning Activity

Neelesh K. Sharma, Mayank Tiwari, Atul Thakur, and Anindya K. Ganguli

Kerbside Waste Collection Round Risk Assessment by Means of Physiological Parameters: sEMG and Heart Rate

Alessio Silvetti, Lorenzo Fiori, Antonella Tatarelli, Alberto Ranavolo, and Francesco Draicchio

Using Complex Biomechanics Models to Communicate

Simple Messages .

Carrie Taylor and Josie Blake

Overview of Measurement-Based Assessment Approaches

from the MEGAPHYS Project

Britta Weber, Kai Heinrich, David H. Seidel, Ingo Hermanns-Truxius,

Ulrike Hoehne-Hückstädt, Dirk Ditchen, Matthias Jäger, Lope H. Barrero, and Rolf Ellegast

Part IV: Ergonomics in Advanced Imaging

(Edited by Jukka Häkkinen)

Effects of Avatars on Street Crossing Tasks in Virtual Reality . . . . . . 215

Philipp Maruhn and Simon Hurst 
Estimating Time to Contact in Virtual Reality:

Does Contrast Matter?

Sonja Schneider, Mariam Salloum, Katharina Gundel, and Annika Boos

Part V: Human Factors in Robotics (Edited by Sascha Wischniewski and Patricia H. Rosen)

Three-Stage Evaluation for Defining the Potential of an Industrial Exoskeleton in a Specific Job

Michiel de Looze, Aijse de Vries, Frank Krause, and Saskia Baltrusch

Human-Robot Collaboration During Assembly Tasks: The Cognitive Effects of Collaborative Assembly Workstation Features .

Federico Fraboni, Luca Gualtieri, Francesco Millo, Matteo De Marchi,

Luca Pietrantoni, and Erwin Rauch

Evaluation of Physiological Costs Using Standardized Analysis

Methods During Simulated Overhead Work with

and Without Exoskeleton

Sandra Groos, Nils Darwin Abele, Petra Fischer, Michael Hefferle, and Karsten Kluth

Development of a Multifunctional Test Station and a Reproducible Test Design for the Evaluation of Stress and Strain During Overhead Work with and Without Upper Body Exoskeletons .

Sandra Groos, Nils Darwin Abele, Kevin Kruse, Petra Fischer,

Michael Hefferle, and Karsten Kluth

Evaluation of Variables of Cognitive Ergonomics in Industrial

Human-Robot Collaborative Assembly Systems . . . . . . . . . . . . . . . 266

Luca Gualtieri, Federico Fraboni, Matteo De Marchi, and Erwin Rauch

Optimizing Force Transfer in a Soft Exoskeleton Using

Biomechanical Modeling.

Christina M. Harbauer, Martin Fleischer, Cerys E. M. Bandmann, and Klaus Bengler

How User Presence Impacts Perceptions and Operation Routines of Robotic Vacuum Cleaners - a 'Stay at Home' Experiment 282

Shanee Honig and Tal Oron-Gilad

Evaluation of Different Degrees of Support in Human-Robot Cooperation at an Assembly Workstation Regarding Physiological

Strain and Perceived Team Fluency . . . . . . . . . . . . . .

Verena Klaer, Hendrik Groll, Jurij Wakula, and Tim Steinebach

Field Study to Objectify the Stress and Strain on Male Workers

During Car Wheel Changes in the Course of Using an Active

Exoskeleton

Karsten Kluth and Michael Hefferle 
Using Multimodal Data to Predict Surgeon Situation Awareness . . . . . 308 Aurelien Lechappe, Mathieu Chollet, Jerome Rigaud, and Caroline G. L. Cao

Preliminary Requirements of a Soft Upper-Limb Exoskeleton for Industrial Overhead Tasks Based on Biomechanical Analysis

Dario Panariello, Stanislao Grazioso, Teodorico Caporaso,

Giuseppe Di Gironimo, and Antonio Lanzotti

A Pilot Study on Auditory Feedback for a Lower-Limb Exoskeleton

to Increase Walking Safety.

Jing Qiu, Yilin Wang, Hong Cheng, Lu Wang, and Xiao Yang

Human-Robot Collaboration (HRC) Technologies for Reducing

Work-Related Musculoskeletal Diseases in Industry 4.0

Alberto Ranavolo, Giorgia Chini, Francesco Draicchio, Alessio Silvetti,

Tiwana Varrecchia, Lorenzo Fiori, Antonella Tatarelli,

Patricia Helen Rosen, Sascha Wischniewski, Philipp Albrecht, Lydia Vogt,

Matteo Bianchi, Giuseppe Averta, Andrea Cherubini, Lars Fritzsche,

Massimo Sartori, Bram Vanderborght, Renee Govaerts,

and Arash Ajoudani

Results from the Third European Survey of Enterprises

on New and Emerging Risks on Human-Robot Interaction

Sascha Wischniewski, Eva Heinold, and Patricia Helen Rosen

Part VI: Human Modelling and Simulation (Edited by Gunther Paul, Gregor Harih and Yue (Sophia) Li)

A Digital Human Modelling-Based Optimization Framework to Minimize Low Back Cumulative Loading During Design of Lifting Tasks

Sivan Almosnino

Assessing the Efficiency of Industrial Exoskeletons with Biomechanical Modelling - Comparison of Experimental and Simulation Results . . . . 353

Lars Fritzsche, Christian Gärtner, Michael Spitzhirn, Pavel E. Galibarov, Michael Damsgaard, Pauline Maurice, and Jan Babič

Current Trends in Research and Application of Digital

Human Modeling

Lars Hanson, Dan Högberg, Erik Brolin, Erik Billing,

Aitor Iriondo Pascual, and Maurice Lamb

Validation of an Inverse Kinematic VR Manikin in Seated Tasks:

Application in Ergonomics Training

Mohammad Homayounpour, Dorien Butter, Saaransh Vasta,

and Andrew Merryweather 
Multi-objective Optimization of Ergonomics and Productivity

by Using an Optimization Framework

Aitor Iriondo Pascual, Dan Högberg, Anna Syberfeldt, Erik Brolin,

Estela Perez Luque, Lars Hanson, and Dan Lämkull

Demographic Effects on Mid-Air Gesture Preference for Control

of Devices: Implications for Design

Haoyan Jiang, Mark Chignell, Sachi Mizobuchi, Farzin Farhadi Niaki,

Zhe Liu, Wei Zhou, and Wei Li

A Human-Centered Design Procedure for Conceptualization Using Virtual Reality Prototyping Applied in an Inflight Lavatory

Meng Li, Doris Aschenbrenner, Daniëlle van Tol, Daan van Eijk, and Peter Vink

Automated Segmentation of 3D Digital Human Model for Area and Volume Measurement

Flavia Cristine Hofstetter Pastura, Tales Fernandes Costa, Gabriel de Aguiar Mendonça, Thatiane dos Santos Lopes, and Maria Cristina Palmer Lima Zamberlan

A Conceptual Framework of DHM Enablers for Ergonomics 4.0 . . . . 403 Gunther Paul and Leyde Briceno

Characterizing Adaptive Display Interventions

for Attentional Tunneling .

Kayla Pedret and Greg A. Jamieson

Digital Production Planning of Manual and Semi-automatic Tasks

in Industry Using the EMA Software Suite

Michael Spitzhirn, Lars Fritzsche, and Sebastian Bauer

Probabilistic Human-System-Integration (HSI) Models: Review

and Extension

Ephraim Suhir and Gunther Paul

Assessment of Biomechanical Risk Factors During Lifting Tasks

in a Spacesuit Using Singular Value Decomposition

Linh Q. Vu, Han K. Kim, and Sudhakar L. Rajulu

A Preliminary Study on the Effects of Foam and Seat Pan Inclination on the Deformation of the Seated Buttocks Using MRI

Xuguang Wang, Léo Savonnet, and Sonia Duprey

Tool Development for Ergonomic Design of Automated Vehicles

Hans-Joachim Wirsching and Martin Fleischer 
Simplifying Ergonomic Assessment for Designers: A User-Product Interaction-Modelling Framework in CAD.

Alexander Wolf, Yvonne Wagner, Marius Oßwald, Jörg Miehling, and Sandro Wartzack

Usability Study on a New Assembly of 3D Interactive Gestures for Human-Computer Interaction

Bohan Wu, Gang Zhang, Xuegang Zhang, Shibo Mei, Jinduo Wu, Hongting $\mathrm{Li}$, and Zhen Yang

Combining a Wearable IMU Mocap System with REBA and RULA for Ergonomic Assessment of Container Lashing Teams .

Sander Zelck, Stijn Verwulgen, Lenie Denteneer, Hanne Vanden Bossche, and Sofia Scataglini

Development of Guidelines for the Ergonomic Evaluation of Human Work in Digital Factory Tools

Gert Zülch

Part VII: Neuroergonomics (Edited by Echezona Nelson Dominic Ekechukwu)

Cognitive Aspects in Control Rooms: Anticipated Response to Adverse Situations

Juan Alberto Castillo-M and Maria Constanza Trillos Ch.

Independent Driving Improved the Self-esteem and Health Related Quality of Life of a Polio Survivor

Olumide Olasunkanmi Dada, Femi Abolaji Ogundapo,

Olusegun Adeyemi Adejare, Chidozie Emmanuel Mbada, and Echezona Nelson Dominic Ekechukwu

Disability and Community Reintegration Among Community

Dwelling Persons Living with Stroke, Spinal Cord Injury and Limb Amputation - A Comparative Study

Echezona Nelson Dominic Ekechukwu, Chinwendu Obi Nwokocha, Blessing Chiagozikam Atuenyi, Antoninus Obinna Ezeukwu, and Olumide Olasunkanmi Dada

Virtual Reality, a Neuroergonomic and Neurorehabilitation Tool for Promoting Neuroplasticity in Stroke Survivors: A Systematic Review with Meta-analysis .

Echezona Nelson Dominic Ekechukwu, Ikenna Collins Nzeakuba, Olumide Olasunkanmi Dada, Kingsley Obumneme Nwankwo, Paul Olowoyo, Victor Adimabua Utti, and Mayowa Ojo Owolabi 
Are the Psychosocial and Physical Disabilities of Stroke Survivors

Ageing Related?

Echezona Nelson Dominic Ekechukwu, Nelson Okogba,

Kingsley Obumneme Nwankwo, Nmachukwu Ifeoma Ekechukwu,

Amaka Gloria Mgbeojedo, Olusegun Adeyemi Adejare,

Uchenna Prosper Okonkwo, and Victor Adimabua Utti

Analyzing the Effect of Visual Cue on Physiological Hand Tremor

Using Wearable Accelerometer Sensors

Vishal Kannan, K. Adalarasu, Priyadarshini Natarajan,

and Venkatesh Balasubramanian

Perceived Barriers and Facilitators of Return to Driving Among

a Sample of Nigerian Stroke Survivors - A Qualitative Study

Kingsley Obumneme Nwankwo, Olubukola Adebisi Olaleye,

Tal'hatu Kolapo Hamzat, and Echezona Nelson Dominic Ekechukwu

VR Application for Vestibular System Training (Pilot Study) . . . . . . . 552

Daria Plotnikova, Aleksandr Volosiuk, Gleb Tikhonov,

Aleksandr Tsynchenko, Anastasiia Luneva, and Artem Smolin

Determination of the Influence of Music on Working Memory

Performance Using EEG Analysis

Minerva Rajendran, Tanya Malaiya, and Venkatesh Balasubramanian

Part VIII: Working with Computer Systems

(Edited by Nicole Jochems)

Empirical Comparison of the Effects of Symmetrical and

Asymmetrical Video Game Console Controllers on Players

Performance.

Asma Alfargani and Ahamed Altaboli

A Novel 3D Editor for Gesture Design Based on Labanotation

Kathleen Anderson, Börge Kordts, and Andreas Schrader

Advancing Towards Automated Ergonomic Assessment:

A Panel of Perspectives

Daniel P. Armstrong, Christopher A. B. Moore, Lora A. Cavuoto,

Sean Gallagher, SangHyun Lee, Michael W. Sonne,

and Steven L. Fischer

From Globalization to Circular Economy, Which Issues for Health

and Safety at Work?

Agnès Aublet-Cuvelier, Michel Hery, and Marc Malenfer 
Collaborative Robotics and Industry 4.0: An Engineering, Sociology and Activity-Centered Ergonomics Cross-Experience.

Flore Barcellini, Willy Buchmann, Richard Béarée,

Tahar-Hakim Benchekroun, Mouad Bounouar, Gérard Dubey,

Caroline Moricot, Anne-Cecile Lafeuillade, Celine Rosselin-Bareille,

Marco Saraceno, and Ali Siadat

Trade-offs of Users and Non-users of Life-Logging - Desire for

Support vs. Potential Barriers

Laura Burbach, Chantal Lidynia, Philipp Brauner, and Martina Ziefle

Enabling Collaborative Situations in 4.0 Industry: Multiple

Case Study

Nathan Compan, Fabien Coutarel, Daniel Brissaud,

and Géraldine Rix-Lièvre

The Impact of Expertise on Query Formulation Strategies During

Complex Learning Task Solving: A Study with Students in Medicine

and Computer Science

Cheyenne Dosso, Lynda Tamine, Pierre-Vincent Paubel,

and Aline Chevalier

Artificial Intelligence (AI) in the Workplace: A Study of Stakeholders'

Views on Benefits, Issues and Challenges of AI Systems

Tamari Gamkrelidze, Moustafa Zouinar, and Flore Barcellini

The Remanufacturing Activity: Skills to Develop and Productive

Organizations to Rethink

Kevin Guelle, Sandrine Caroly, and Aurélie Landry

Steady Hands - An Evaluation on the Use of Hand Tracking in Virtual

Reality Training in Nursing

Tino Hentschel and Jan A. Neuhöfer

Supporting Pain Management for Mechanically Ventilated Intensive Care Patients Using a Novel Communication Tool

Jan Patrick Kopetz and Nicole Jochems

Users' Error Recovery Strategies in the Interaction with Voice

Assistants (VAs)

Isabela Motta and Manuela Quaresma

User Needs for Digital Creativity Support Systems in an

Occupational Context

Lorenz Prasch, Lena aus dem Bruch, and Klaus Bengler

An Empirical Study on Automation Transparency (i.e., seeing-into) of an Automated Decision Aid System for Condition-Based

Maintenance.

Fahimeh Rajabiyazdi, Greg A. Jamieson, and David Quispe Guanolusia 
A User Study to Evaluate the Customization of Automatically

Generated GUIs

David Raneburger, Roman Popp, and Hermann Kaindl

A Framework for Future Navigation Aids

Adam J. Reiner, Greg A. Jamieson, and Justin G. Hollands

Explainable AI for Entertainment: Issues on Video

on Demand Platforms.

Cinthia Ruiz and Manuela Quaresma

Reliability of Heuristic Evaluation During Usability Analysis

Thomas J. Smith and Cindy Kheng

Clinical Usability Studies - Clash of Cultures? Study Design Proposal

from Lessons Learned

Thomas Stüdeli and Limor Hochberg

Collaborating with Communities in Participatory System

Development

Torben Volkmann, Michael Sengpiel, and Nicole Jochems

Making Tax eForms Less Taxing-Comparing Evaluation Measures of User-Experience, Usability, and Acceptance in Public Sector

eForms

Mourad Zoubir, Daniel Wessel, Tim Schrills, Thomas Franke, and Moreen Heine

Part IX: Ergonomic Work Analysis and Training (EWAT) Addendum (Edited by Catherine Delgoulet and Marta Santos)

Learning Scenarios for the Improvement of Operating Safety of Machine Tools .

Leif Goldhahn and Robert Eckardt

Developing a Training Action for Primary School Teachers by Doubly Considering (Their) Work . . . . . . . . . . . . . . . . . . . . 758

Ana Rodrigues, Maria Cadilhe, Filipa Ferreira, Cláudia Pereira, and Marta Santos

Part X: HF/E Education and Professional Certification Development Addendum (Edited by Chien-Chi (Max) Chang and Maggie Graf)

Applications and Implications of the Brazilian Ergonomics Regulatory Standard (NR17)

Lia Buarque de Macedo Guimarães, Marcia Gemari Derenevich, and Rosimeire Sedrez Bitencourt 
Part XI: Organisation Design and Management (ODAM) - Addendum (Edited by Laerte Idal Sznelwar)

Occupational Safety and Protection Against Infection in Times of the Pandemic: Challenges for Human Factors and Regulation

Thomas Alexander, Lars Adolph, and Stefan Voss

Presenteeism and Voice: Ergonomic Factors for Sports Coaches

Katie Buckley, Jennifer Oates, Paul O’Halloran, Mandy Ruddock-Hudson, and Lindsay Carey

Ergo@Large: Collaborating for the Benefits of $\mathrm{HF} / \mathrm{E}$ 791 Jeanne Guérin

A Synthesis of Subjective Scales Which Assess Worker Fatigue:

Building a Simple, Reliable, and Effective Evaluative Instrument

Gabriella M. Hancock, Mira Gruber, Uyen D. Bui, Jessica Blay-Moreira, Yvette Apatiga, Christian E. Schmitz, and Peter A. Hancock

Heat Stress Management in the Construction Industry:

A Socio-technical Systems Perspective 804

Damithri Gayashini Melagoda and Steve Rowlinson

Attitude Towards Artificial Intelligence in a Leadership Role

Deborah Petrat

Macroergonomics-Based Approach for a Management Trainee

Program in the Utilities Industry

Yogi Tri Prasetyo and Johnamae Khow

Part XII: Systems HF/E - Addendum (Edited by Paul M. Salmon)

Human Factors Effects on a Human-Robot Collaboration System:

A Modelling Approach

Guilherme Deola Borges, Paula Carneiro, and Pedro Arezes

Part XIII: Slips, Trips and Falls - Addendum

(Edited by Richard Bowman)

The Future of Footwear Friction

Kurt E. Beschorner, Yue (Sophia) Li, Takeshi Yamaguchi, William Ells, and Richard Bowman

Effects of Foot-Floor Friction on Trip-Induced Falls During Shuffling

Gait: A Simulation Study . . . . . . . . . . . . . . . . . . . . . 856

Takeshi Yamaguchi, Kenichi Nakatani, Tomoki Hirose, Takashi Yoshida, and Kei Masani

Author Index 